\title{
Ultrasonic-Assisted Extraction (UAE) for Enhanced Recovery of Bioactive Phenolic Compounds From Cosmos Caudatus Leaves
}

NORLIZA LATIFF ( $\sim$ norlizaabdlatiff@utm.my )

Universiti Putra Malaysia

\section{PEI YING ONG}

University of Technology Malaysia

LUQMAN CHUAH ABDULLAH

Universiti Putra Malaysia

SITI NOR AZLINA ABD RASHID

University of Technology Malaysia

NOOR AKHMAZILLAH MOHD FAUZI

Tun Hussein Onn University of Malaysia

Noor Amaiza Mohd Amin

Universiti Putra Malaysia

\section{Research Article}

Keywords: Cosmos caudatus leaves, UAE, quercitrin, phenolic, response surface methodology

Posted Date: January 20th, 2021

DOI: https://doi.org/10.21203/rs.3.rs-143469/v1

License: (c) (i) This work is licensed under a Creative Commons Attribution 4.0 International License.

Read Full License 


\title{
Ultrasonic-Assisted Extraction (UAE) for Enhanced Recovery of Bioactive Phenolic compounds from Cosmos Caudatus leaves
}

\author{
Norliza Abdul Latiff ${ }^{1,3^{*}+}$, Pei Ying Ong ${ }^{3}$, Luqman Chuah Abdullah ${ }^{1^{*}}$, Siti Nor Azlina Abd \\ Rashid ${ }^{3}$, Noor Akhmazillah Mohd Fauzi ${ }^{4}$ and Noor Amaiza Mohd Amin² \\ 1 Department of Chemical and Environmental Engineering, Faculty of Engineering, Universiti Putra \\ Malaysia, Serdang, 43400, Selangor, Malaysia; norlizaabdlatiff@utm.my (N.A.L); chuah@upm.edu.my \\ (L.C.A) \\ 2 Department of Process and Food Engineering, Faculty of Engineering, Universiti Putra Malaysia, Serdang, \\ 43400, Selangor, Malaysia; myza@upm.edu.my (N.A.M.A) \\ 3 Innovation Centre in Agritechnology, Universiti Teknologi Malaysia, Muar, 84600, Johor, Malaysia; \\ o.peiying@utm.my (P.Y.O), sitinorazlina@utm.my (S.N.A.A.R) \\ 4 Department of Chemical Engineering Technology, Faculty of Engineering Technology, Universiti Tun \\ Hussein Onn Malaysia, Pagoh Higher Education Hub, Muar, 84600, Johor, Malaysia; akhma@uthm.edu.my \\ (N.A.M.F) \\ * Correspondence: chuah@upm.edu.my; Tel: +60-3-86567120; norlizaabdlatiff@utm.my; Tel.: +60-6-9742856
}

Received: date; Accepted: date; Published: date

\begin{abstract}
Cosmos caudatus (C. caudatus) is one of the common medicinal plants and among the valuable plants that are high in bioactive compounds such as phenolics. In this study, an ultrasoundassisted extraction (UAE) method was used to optimise the extraction of bioactive compounds from C. caudatus leaves using response surface methodology (RSM) and employing a Box-Behnken experimental design (BBD). The extraction efficiency of UAE under the optimal extraction conditions was compared with the Soxhlet method. Also, an anti-microbial analysis against two human pathogenic bacteria; Staphylococcus aureus (S. aureus) and Escherichia coli (E. coli) was also evaluated. The effect of the extraction conditions was studied and optimised such as the solid-liquid ratio (10 to $30 \mathrm{~g} / \mathrm{ml})$, particle size (180 to $850 \mu \mathrm{m}$ ) and extraction time (20 to $30 \mathrm{~min})$. Quercitrin and total phenolic content (TPC) were the selected response variables in this study. Based on the ANOVA analysis, the response surface model to predict the optimum yield of quercitrin and TPC was adequate with a high R-square value corresponding to 0.9930 and 0.9962 . The optimal UAE conditions were 1:28 (g/mL), by using a particle size of $485 \mu \mathrm{m}$ and an extraction time of $30 \mathrm{~min}$, respectively. Remarkably, UAE reduced the extraction time and solvent volume, with the maximal recovery of bioactive compounds at a high antioxidant activity as compared with that of the Soxhlet method. The plant extract also exhibited potential microbial agents. Due to the above findings, UAE can be used to enrich quercitrin and total phenolic content from C. caudatus leaves. It also opens the possibility of plant extract to be used as an affordable component in many applications such as food formulations and anti-microbial agents.
\end{abstract}

Keywords: Cosmos caudatus leaves; UAE; quercitrin; phenolic; response surface methodology

\section{Introduction}

Cosmos caudatus (C. caudatus) is widely used as a traditional folk medicine among communities such as Malay and Javanese around South-East Asian countries ${ }^{1,2}$. The leaves and shoots can be eaten raw as a vegetable or as a side dish during meals, and for other culinary purposes 1,3 . The plant extract from leaves possesses an excellent source of antioxidants and phenolic compounds as dominant compounds. Based on scientific evidence, the plant extract displays various pharmacological properties such as anti-bacterial, anti-inflammatory, bone-protective agent, and antidiabetic 1,4-6. Moreover, the extract of $C$. caudatus leaves has a strong antioxidant property and the content is higher 
compared to some tropical fruits, herbs, and vegetables 7,8 . In addition, the plant is also rich in vitamins (B1, B2, C and $\beta$-carotene) and minerals (potassium, calcium, magnesium, phosphorus, iron, zinc, sodium and copper) ${ }^{2,9}$. Quercetin glycosides, namely quercitrin has been identified to be the dominant phenolic compound from the leaf extract ${ }^{10-12}$. Previous studies have shown that quercitrin has strong antioxidant, anti-bacterial, osteoblast protection, and has been used for allergic prevention 13-15. Considering the beneficial prospects of $C$. caudatus leaves extract as a source of natural antioxidants such as quercitrin, an efficient extraction process should be developed for extracting the quercitrin and phenolic compounds from the plant matrix.

A strategy to save production cost, energy, and time, as well as applying the green concept, has motivated researchers to establish various eco-friendly plant extraction methods ${ }^{16-18}$. The methods utilise various modifications with either ultrasonic, microwave, ultra-high pressure or supercritical fluid extractions assistance ${ }^{16,19}$. Ultrasound-assisted extraction (UAE) could be the better choice and has become a promising green extraction technology among the established methods ${ }^{16,20,21}$. It provides a faster, simpler operation method, high reproducibility and is suitable for thermo-labile compounds 22-24. The extraction efficiency can be increased by the effect of acoustic cavitation in the solvent that leads to the disruption or breakdown of plant cell walls. This mechanism accelerates faster movement of molecules and increases the mass transfer process in contact with solid material during the extraction process ${ }^{25,26}$. The extraction efficiency of UAE is underlined by different extraction parameters such as ultrasonic irradiation time, temperature, frequency, the ratio between solvent to solid ratio (SLR) and solvent types ${ }^{27,28}$. Likewise, the applied extraction parameters should be carried out under their optimal conditions to produce a high recovery of targeted extraction yield. This can be achieved by carrying out a statistical design based on response surface methodology (RSM) ${ }^{24}$.

The factorial design obtained by RSM allows the effects of multiple-variables and also their interaction to be evaluated simultaneously 29,30 . The factorial design includes three major steps: (1) set the independent variables and responses, in which the number of variables and their levels is decided from a preliminary experiment; (2) interpretation of response surface modelling using contour (2D) and surface plot (3D) interaction among the variables; (3) model validationn ${ }^{31}$. Different factorial designs can be performed such as Box-Behnken or Central Composite design. The Box-Behnken design has better data accuracy, is more cost-effective and considerably less experimental runs care required ompared to the classical approach ${ }^{16,31}$. Various types of sample matrix can be applied in the Box-Behnken experimental design for extraction of the phenolic compounds such as samara oil 32, algae ${ }^{31}$, glutinous rice bran ${ }^{33}$, cherry fruits ${ }^{24}$, Ilex guayusa Loes. leaves ${ }^{34}$ and Citrus medica ${ }^{16}$.

Studies conducted elsewhere have revealed various extraction methods for C. caudatus ${ }^{35-3936-39}$. However, many of these methods only focus on the recovery yield of total phenolics and antioxidants $35,38,40$. There are no reports concerning the recovery yield of quercitrin, which is presently major aspect of $C$. caudatus leaves extract. Therefore, this study is carried out to optimise the UAE process for a maximal yield of quercitrin and total phenolic content from C. caudatus leaves. The extraction method of UAE was optimised using response surface methodology, utilising the Box-Behnken design. Moreover, the UAE yields were compared with the results obtained by the Soxhlet extraction method. Further, the analysis of antimicrobial activity was performed to evaluate the potential of plant extract as antimicrobial agent against two humans pathogenic: Staphylococcus aureus (S. aureus) and Escherichia coli (E. coli). 


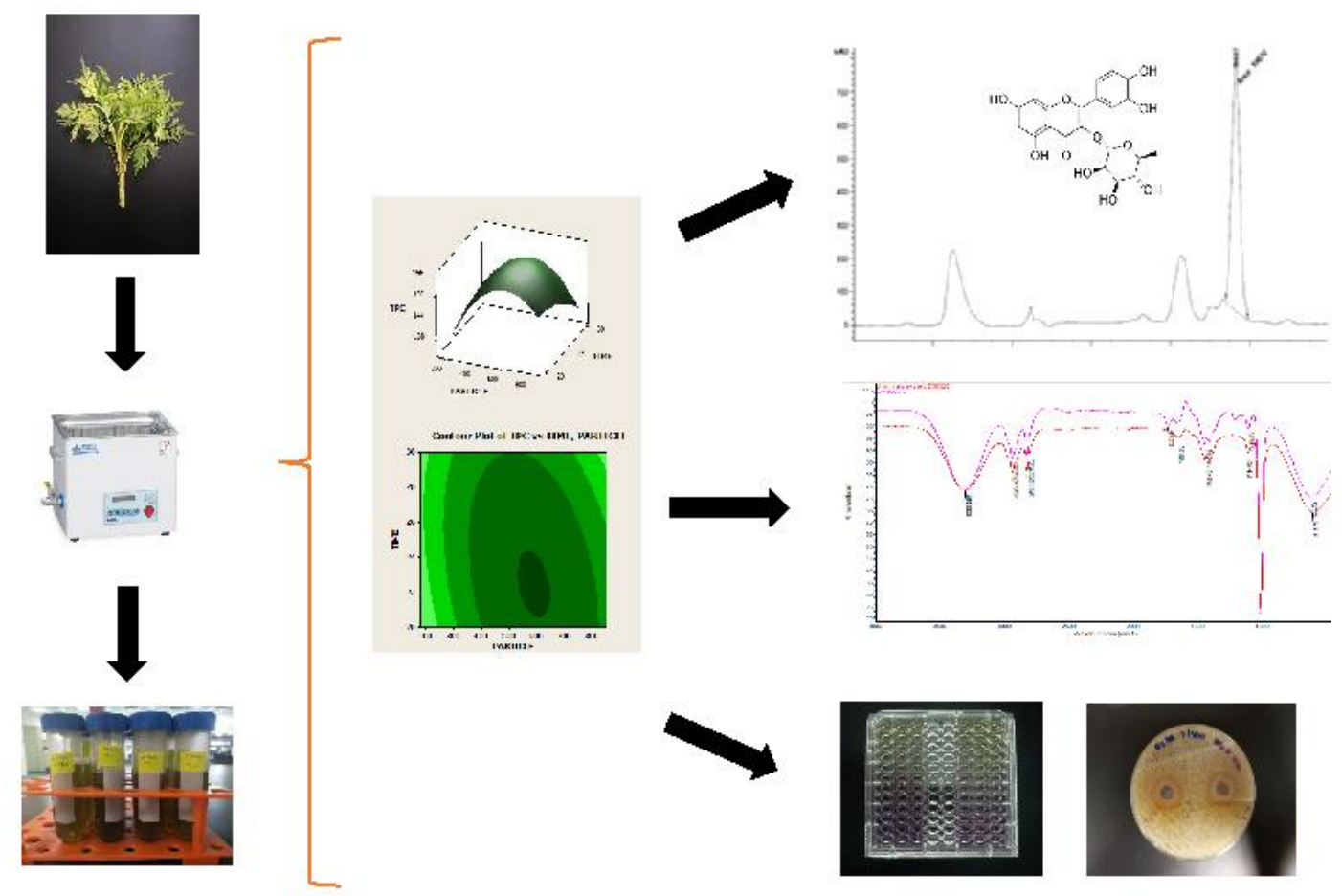

Figure 1. Process flow of the studied extraction process

\section{Materials and Methods.}

\section{Preparation of Cosmos caudatus extract.}

Cosmos caudatus (C. caudatus) was harvested and collected from the university's research farm of Universiti Teknologi Malaysia, located at Pagoh, Johor. The fresh leaf parts were dried at $40^{\circ} \mathrm{C}$ for $4 \mathrm{~h}$ in a laboratory oven dryer (Mediani et al. 2014). The dried leaves were subsequently ground into a powder and sieved (Wstyler, Mentor, OH, USA). The samples obtained were kept and sealed in an air-tight container and maintained at $-25^{\circ} \mathrm{C}$ until further used.

Chemicals and Reagents. Quercitrin and gallic acid (3,4,5-trihydroxy benzoic acid, 99\%) and Folin-Ciocalteu phenol reagent, $\mathrm{Na}_{2} \mathrm{CO}_{3}$, formic acid (HPLC grade) was procured from Sigma Aldrich (Steinheim, Germany). Ethanol (reagent grade) was purchased from Across Organics (Leicestershire, England). Methanol (HPLC grade) and Acetonitrile (HPLC grade) were obtained from Daejung Company, Ltd. (Busan, South-Korea).

Ultrasonic- Assisted Extraction. Ultrasonic-assisted extraction was carried out in an ultrasonic bath device (WiseD; Daihan Scientific, Ltd Co, South-Korea) and operated at a constant frequency of $40 \mathrm{kHz}$ and with a power of $175 \mathrm{~W}$. The device is equipped with a digital system to control extraction time and the ultrasonic bath temperature. The leaf samples were immersed directly into a $100 \mathrm{~mL}$ glass beaker containing a solvent $(80 \% \mathrm{v} / \mathrm{v}$ ethanol) and extracted following the conditions as designated by the Box-Behnken experimental design. The solvent temperature was pre-set at a constant $50{ }^{\circ} \mathrm{C}$. After completion of the extraction process, the samples were filtered in a vacuum pump and the clear supernatant was transferred into a centrifuge tube and concentrated until dryness using a concentrator centrifuge (Concentrator plus, Hamburg, Germany). Afterwards, the crude extract was refrigerated at $-25^{\circ} \mathrm{C}$ to minimise degradation of the bioactive compounds caused by oxidation, prior to subsequent analysis. 
Yield of crude extract was calculated as:

$$
\text { Crude extract yield }(\%)=\frac{\text { Dry mass of crude extract }}{\text { mass of raw material }} \times 100
$$

(1)

Conventional extraction by Soxhlet. Extraction was performed using the Soxhlet apparatus. The leaf sample was placed in a thimble chamber and inserted into the thimble holder condenser. It was attached to a $250 \mathrm{~mL}$ distillation flask. The sample $(1 \mathrm{~g})$ and $80 \%$ ethanol volume $(200 \mathrm{~mL})$ were used for the extraction process. The extraction was maintained for $5 \mathrm{~h}$ at $80^{\circ} \mathrm{C}$. After completing the extraction, the residue was filtered in a vacuum pump and concentrated until dryness using a solvent centrifugal concentrator (Concentrator plus, Hamburg, Germany). The samples were kept refrigerated at $-25^{\circ} \mathrm{C}$ before analysis.

High-performance liquid chromatography analysis. The chromatographic analysis of quercitrin from C. caudatus leaf extract was done using a 1290 Infinity HPLC coupled with a diode array detector system (HPLC-DAD) (Agilent Technologies, Santa Clara, CA, USA). A reverse-phase column (Inertsil ODS, $5 \mu \mathrm{m}, 250 \mathrm{~mm} \times 4.6 \mathrm{~mm}$ I.D.) was used for separation of the compound. The analysis was according to Sharifuldin et al. ${ }^{10}$ with some adjustments. The injection volume was $10 \mu \mathrm{L}$. The elution set were $0.3 \%$ formic acid in water (A) and $100 \%$ acetonitrile (B) with the following sequence of A distributions as follows: $0.01 \mathrm{~min}-80 \%, 10 \mathrm{~min}-50 \%, 11 \mathrm{~min}-0 \%, 14 \mathrm{~min}-80 \%$. The separation was achieved at a flow rate of $0.5 \mathrm{~mL} / \mathrm{min}$ for a $14 \mathrm{~min}$ run time. The detection wavelength of quercitrin was achieved at $260 \mathrm{~nm}$ and the wavelength was integrated by OpenLab software (Agilent Technologies, Santa Clara, CA, USA). The quercitrin content was calculated using a linear regression equation that was obtained from the standard calibration curve of quercitrin. Before the injection, all samples were filtered using a nylon membrane $0.45 \mu \mathrm{m}$. The experiments were conducted in triplicate. The quercitrin content was calculated using the equation below:

$$
\text { Quercitirn content }(\mathrm{mg} / \mathrm{g})=\frac{\text { Concentration }\left(\frac{\mathrm{mg}}{\mathrm{L}}\right) * \operatorname{volume}(\mathrm{L})}{\text { mass of } \operatorname{crude} \operatorname{extract}(\mathrm{g})}
$$

Total phenolic content analysis by UV-spectrophotometric. The total phenolic content of the leaf extract was analysed using the UV-spectrophotometric method by Safdar et al. ${ }^{41}$ with modifications. Briefly, a set of $40 \mu \mathrm{L}$ extracts were added into a 96-well plate, followed by $100 \mu \mathrm{L}$ Folin-Ciocalteau's reagent (10-fold diluted). After 5 min of reaction, $80 \mu \mathrm{L}$ of $\mathrm{Na}_{2} \mathrm{CO}_{3}(7.5 \mathrm{~g} / 100 \mathrm{~mL})$ was added to the sample solutions. The samples were shaken and incubated at ambient temperature $\left(26^{\circ} \mathrm{C}\right)$ for the development of a blue colour. After $90 \mathrm{~min}$, the samples were measured at an absorbance at $765 \mathrm{~nm}$ using an ELISA microplate reader (VersaMax, Molecular Devices, LLC, USA). The total phenolic content was expressed as mg gallic acid equivalents (GAE) per g of extract. All experiments were conducted in triplicate.

Fourier Transform Infrared (FTIR) analysis. The spectrum of the bioactive compound in the leaf extract was recorded using Fourier Transform Infrared spectrometer (Nicolet ${ }^{\mathrm{TM}}$ iS $^{\mathrm{TM}} 5$ FTIR Spectrometer, Thermo Fisher) based on the method by Saidan et al. ${ }^{42}$ with modifications. The wavelength was recorded in the region from 4000 to $600 \mathrm{~cm}^{-1}$ with 30 scans and each spectrum was accumulated by the attenuated total reflection diamond (ATR) device. The spectral data was analysed and processed using Omnic software (Thermo Scientific, USA). The ATR diamond was carefully cleaned with ethanol between measurements and dried before analyzing a new sample.

Antimicrobial analysis. Two clinical human pathogenic bacteria; Staphylococcus aureus (S. aureus) and Escherichia coli (E. coli) were used to determine the antimicrobial potential using the agar well diffusion method ${ }^{43}$. The nutrient agar was inoculated with bacteria and treated with the $50 \mu \mathrm{l}$ plant extract. After the incubation period of $24 \mathrm{~h}$ under a controlled temperature $\left(30^{\circ} \mathrm{C}\right)$, the diameter 
of the inhibition zone was measured. Standard antibiotic of a Streptomycin $(10 \mu \mathrm{g})$ was used control in this study.

Optimization of UAE extraction by Box-Behnken experimental design. Prior to the experiment, a single-factor experiment was performed to determine the effect of four extraction variables (solid to liquid ratio, particle size, amplitude, and time) on extraction yields (quercitrin and total phenolic content). The study was performed over a total of 19 tests with three replicates for each test to analyse the effect and its appropriate levels of extraction variables. In the second stage, a three-level BoxBehnken design (BBD) was performed to determine the optimal levels for the selected extraction variables with their corresponding range: solid to liquid ratio $\left(X_{1}\right): 10,20,30$; particle size $\left(X_{2}\right) 180$, $515,850 \mu \mathrm{m}$; and time $\left(X_{3}\right): 120,25,30$, as presented in Table 1 . The other parameters were maintained constant such as extraction solvent ( $80 \%$ ethanol) and amplitude level $(40 \%)$. The effect of the variables and the statistical performance among the data was evaluated using analysis of variance (ANOVA). The mean value data from the experimental works was fitted in a second-order polynomial equation to predict the responses as presented in Equation 3.

$$
\mathrm{Y}=\beta_{0} \sum_{\mathrm{i}=1}^{\mathrm{k}} \beta_{i} x_{i}+\sum_{\mathrm{i}=1}^{\mathrm{k}} \beta_{i i} x^{2}{ }_{i}+\sum_{1 \leq \mathrm{i} \leq \mathrm{j}}^{\mathrm{k}} \beta_{i j} x_{i} x_{j}
$$

where, $\mathrm{Y}$ represents the predicted response, $\mathrm{k}$ is the number of factors determined (3) in this study, $\beta_{0}, \beta_{i}, \beta_{i i}, \beta_{i j}$ represent the coefficients term as linear, quadratic, and interactive, respectively, $x_{i}, x_{i i}$, and $x_{i j}$ are the coded independent factors ${ }^{16,44}$

The statistical data (p-value) among the independent and coefficient terms were evaluated by the ANOVA method and data was generated using Minitab 16.0 software. The result with small p-value and larger F-value indicates that the model term was significant ${ }^{45,46}$. Contour and surface plots were also generated to visualize the interaction among the independent variables.

\begin{tabular}{|c|c|c|c|}
\hline Factors & \multicolumn{3}{|c|}{ Independent variables } \\
\hline Levels & $\mathrm{X}_{1}(\mathrm{~g} / \mathrm{mL})$ & $X_{2}(\mu \mathrm{m})$ & $\mathrm{X}_{3}(\mathrm{~min})$ \\
\hline-1 & 10 & 180 & 20 \\
\hline 0 & 20 & 515 & 25 \\
\hline+1 & 30 & 850 & 30 \\
\hline
\end{tabular}

Table 1. The selected independent variables for the BBD experimental design

\section{Results and Discussion}

UAE parameter optimisation. In this study, the Box-Behnken design was performed to determine the optimal UAE of the independent variables for the extraction of quercitrin and total phenolic content from C. caudatus leaves. An extraction model based on a second-order polynomial equation was then developed. The results obtained from actual works and predicted values by the second-order polynomial equation model are shown in Table 2 . The actual values of quercitrin ranged from 20.81 to $54.11 \mathrm{mg} / \mathrm{g}$ DW, while the predicted values ranged from 21.05 to $55.45 \mathrm{mg} / \mathrm{g}$ DW. For the total phenolic content, the actual values ranged from 119.72 to $188.28 \mathrm{mg}$ GAE/g DW, while the predicted values ranged from 118.05 to $188.78 \mathrm{mg}$ GAE/g DW. Data of analysis of variance (ANOVA) of the predicted models is displayed in Table 3. In this study, the model for the two responses was significant. The presented data showed the best fit with higher R-square value corresponding to 0.9930 for quercitrin and 0.9962 for total phenolic content. The adjusted R-squared value for quercitrin was 0.8969 and close to the 0.9930 , while the adjusted R-squared value total phenolic content was 0.9952 and close to the 0.9953 . Both predicted R-square values were in 
reasonable agreement, where the difference was less than $0.2{ }^{16}$. Also, the lack of fit was nonsignificant and thus showing high precision to fit with the model ${ }^{24}$. The developed models were satisfactory to describe the connection between the independent variables and the response variables.

The positive and negative sign of the coefficient shown also related to its effect, for such sign of increase or decrease of value. In the case of quercitrin, the solid to liquid ratio and time was the most significant effect in the linear term, both showing a negative coefficient value, while particle size showed a less significant effect with a positive coefficient sign. The quadratic term between three variables had a greater effect to influence the quercitrin yield, whereas the interactive effect was only significant with a negative sign between the solid to liquid ratio and extraction time. This implies that the higher yield of quercitrin could be achieved when reducing the solid to liquid ratio and extraction time. After considering an only significant effect, the final regression model of quercitrin was determined as follows:

$$
\begin{aligned}
\text { QR content }\left(\mathrm{Y}_{1}\right)= & 151.264-0.964 \mathrm{X}_{1}-9.135 \mathrm{X}_{3}-0.062 \mathrm{X}_{1^{2}}-6.932 \times 10^{-5} \mathrm{X}_{2^{2}}+0.153 \mathrm{X}_{3}{ }^{2} \\
& +0.105 \mathrm{X}_{1} \mathrm{X}_{3}
\end{aligned}
$$

For the total phenolic content, among the independent variables, only the solid to liquid ratio displayed a strong significant linear effect with a negative coefficient sign. The quadratic term was significant and corresponded to the solid to liquid ratio and particle, except for the extraction time. The interactive effect of particle and time was significant and had a greater effect on the total phenolic content. The negative coefficient denoted that decreasing the particle size and extraction time to a certain level could result in higher total phenolic content while applying a higher SLR could increase the yield. As for the final equation for prediction of total phenolic content, after excluding the insignificant terms, the final equation was given by:

Total phenolic content $\left(\mathrm{Y}_{2}\right)=41.933-0.582 \mathrm{X}_{1}+0.094 \mathrm{X}^{2}-7.204 \times 10^{-5} \mathrm{X}_{2}{ }^{2}-0.002 \mathrm{X}_{2} \mathrm{X}_{3}$

\begin{tabular}{cccccccc}
\hline & & & \multicolumn{2}{c}{ Quercitrin, $(\mathrm{mg} / \mathrm{g})$} & \multicolumn{2}{c}{ Total phenolic content $(\mathrm{mg} / \mathrm{g})$} \\
\hline Run no. & $\mathrm{X}_{1}$ & $\mathrm{X}_{2}$ & $\mathrm{X}_{3}$ & Experimental & Predicted & Experimental & Predicted \\
\hline 1 & 30 & 515 & 20 & 25.85 & 26.09 & 188.28 & 188.78 \\
2 & 10 & 515 & 30 & 49.14 & 49.41 & 125.42 & 125.36 \\
3 & 30 & 180 & 25 & 22.08 & 22.94 & 178.72 & 177.65 \\
4 & 10 & 515 & 20 & 54.11 & 55.45 & 126.39 & 127.51 \\
5 & 10 & 180 & 25 & 40.31 & 40.07 & 119.75 & 118.05 \\
6 & 30 & 850 & 25 & 20.81 & 21.05 & 180.96 & 182.65 \\
7 & 20 & 180 & 30 & 43.87 & 44.35 & 137.60 & 139.79 \\
8 & 20 & 850 & 20 & 40.15 & 39.67 & 149.12 & 146.93 \\
9 & 20 & 515 & 25 & 45.92 & 45.39 & 148.56 & 148.65 \\
10 & 20 & 515 & 25 & 45.58 & 45.39 & 146.56 & 148.65 \\
11 & 20 & 850 & 30 & 41.90 & 43.07 & 136.20 & 135.63 \\
12 & 10 & 850 & 25 & 42.50 & 41.58 & 120.30 & 121.37 \\
13 & 30 & 515 & 30 & 42.46 & 41.11 & 186.09 & 184.97 \\
14 & 20 & 180 & 20 & 38.98 & 38.71 & 133.88 & 134.45 \\
15 & 20 & 515 & 25 & 44.67 & 45.39 & 150.82 & 148.65 \\
\hline
\end{tabular}


Table 2. BBD model fitness for optimum yield of quercitrin and total phenolic from C. caudatus leaves

\begin{tabular}{|c|c|c|c|c|}
\hline & \multicolumn{2}{|c|}{$Y_{1}$} & \multicolumn{2}{|c|}{$\mathrm{Y}_{2}$} \\
\hline & Coef & $\mathrm{p}$-value & Coef & $\mathrm{p}$-value \\
\hline$\beta_{0}$ & 151.264 & & 41.933 & \\
\hline Linear & & $0.000^{*}$ & & $0.000^{*}$ \\
\hline $\mathrm{X}_{1}$ & -0.964 & $0.000^{*}$ & -0.582 & $0.000^{*}$ \\
\hline$X_{2}$ & 0.085 & 0.852 & 0.140 & 0.063 \\
\hline$X_{3}$ & -9.135 & $0.005^{*}$ & 3.871 & 0.148 \\
\hline Quadratic & & $0.000^{*}$ & & $0.001^{*}$ \\
\hline$X_{1^{2}}$ & -0.062 & $0.000^{*}$ & 0.094 & $0.001^{*}$ \\
\hline $\mathrm{X}_{2^{2}}$ & -6.932 & $0.000^{*}$ & $-7.204 \times 10-5$ & $0.001^{*}$ \\
\hline$X_{3^{2}}$ & 0.153 & $0.003^{*}$ & -0.054 & 0.337 \\
\hline Interaction & & $0.003^{*}$ & & 0.089 \\
\hline$X_{1} X_{2}$ & $-2.542 \times 10^{-4}$ & 0.263 & $1.254 \times 10-4$ & 0.747 \\
\hline$X_{1} X_{3}$ & 0.1053 & $0.001^{*}$ & -0.008 & 0.749 \\
\hline $\mathrm{X}_{2} \mathrm{X}_{3}$ & 3.419 & 0.435 & -0.002 & $0.020^{*}$ \\
\hline $\mathrm{R}^{2}$ & 99.30 & & 99.62 & \\
\hline Adj. $R^{2}$ & 89.69 & & 95.53 & \\
\hline Pre. $R^{2}$ & 98.04 & & 98.95 & \\
\hline Lack of fit & 0.135 & & 0.413 & \\
\hline
\end{tabular}

Table 3. Analysis of variance (ANOVA) of the predicted models for quercitrin and total phenolic from C. caudatus leaves

Analysis of the Contour and Surface Plot. The two-dimensional (2D) contour and threedimensional (3D) surface plots are used to graphically represent the interactive effects of the studied variables with respect to the responses ${ }^{34}$. The responses plots of quercitrin content were presented in Figure $2(a-c)$, while Figure $3(a-b)$ shows the response plots of total phenolic content. From these generated plots, the results found that the UAE extraction performed at a lower particle size would increase the quercitrin (Fig. 2a) and total phenolic content (Fig. 3a) in the sample extract. In theory, raw materials with smaller particle size enable a better mass transfer process due to enlarging the contact surface area of the samples with solvent ${ }^{47,48}$. However, the extraction efficiency would also be reduced when a very small particle-like powder was used. Vuong with his team ${ }^{49}$ reported decreasing tea particle size formed sediment at the bottom of the extraction vessel and also require more operational cost for accessing the grinding and filtration process Azri50 reported a suitable particle size for higher quercitrin yield from Melastoma malabthricum leaves using the UAE was 450 $\mu \mathrm{m}$. In Pandan leaf samples, Yahya and friends ${ }^{51}$ reported the yield of crude extract was successfully increased by up to $50 \%$ using a smaller particle size. The SLR was found to be a significant factor to increase in the yield of quercitrin and TPC content. The interaction effects between particle size and SLR suggests that SLR of 1:15 g/ml (Fig. 2c) and 1:30 g/ml (Fig. 3c) favoured an increase in the yield of quercitrin and total phenolic content from the plant sample. Higher SLR can promote the access of solvent into the material and thereby facilitate the cavitation effect ${ }^{52}$. This cavitation is known to cause particle collisions and cell wall disruption that facilitates mass transfer 28,53. Based on observation, decreasing the SLR up to 1:15 gives the best yield of quercitrin as a targeted phenolic 
compound while after exceeding a certain level of SLR, it will reduce the performance of quercitrin to diffuse out from the sample matrix. As seen in Fig $2 b$ and $2 c$, utilising a longer exposure time to ultrasonic waves also increases the extraction efficiency of quercitrin and total phenolic yield, as it promotes the extension and degradation of the cell wall and the release of the target analytes. In previous work by Zulkiply ${ }^{40}$ it was found that a longer sonication time $(300 \mathrm{~min})$ increases the yield of phenolic content in the $C$. caudatus leaves extract using an ultrasonic bath system. However, in some cases, extraction efficiency may decrease due to prolonged sonication time as it would reduce the permeability of the solvents to the cell walls due to over-suspended impurities and affected mass transfer 28,50 .

Predicted optimal extraction conditions and verification. The optimal conditions of the studied variables were determined by setting the goal at the maximum responses using the optimiser plot. The maximum predicted yield of quercitrin was $44.26 \mathrm{mg} / \mathrm{g}$, and total phenolic content was 175.64 $\mathrm{mg} / \mathrm{g}$ using SLR 1: 28 (g/mL), particle size $485 \mu \mathrm{m}$ and extraction time $30 \mathrm{~min}$. The overall desirability respecting the following conditions was 0.9508 . The experimental values under these optimal conditions were close to the predicted values with \% error of $3.81 \%$ for quercitrin and $3.72 \%$ for the total phenolic content (Table 4). The experimental values of quercitrin and total phenolic content were recorded as $42.57 \mathrm{mg} / \mathrm{g}$ and $169.75 \mathrm{mg} / \mathrm{g}$ respectively. Through this validation study, the abovedeveloped regression models were found to be suitable to optimise the UAE process.

\begin{tabular}{cccc}
\hline Responses & Experimental & Predicted & \% Error \\
\hline Quercitrin, $(\mathrm{mg} / \mathrm{g})$ & 42.57 & 44.26 & 3.81 \\
\hline Total phenolic content, $(\mathrm{mg} / \mathrm{g})$ & 169.75 & 175.64 & 3.72
\end{tabular}

Table 4. Validation of quercitrin and total phenolic content under optimal UAE conditions

(a)

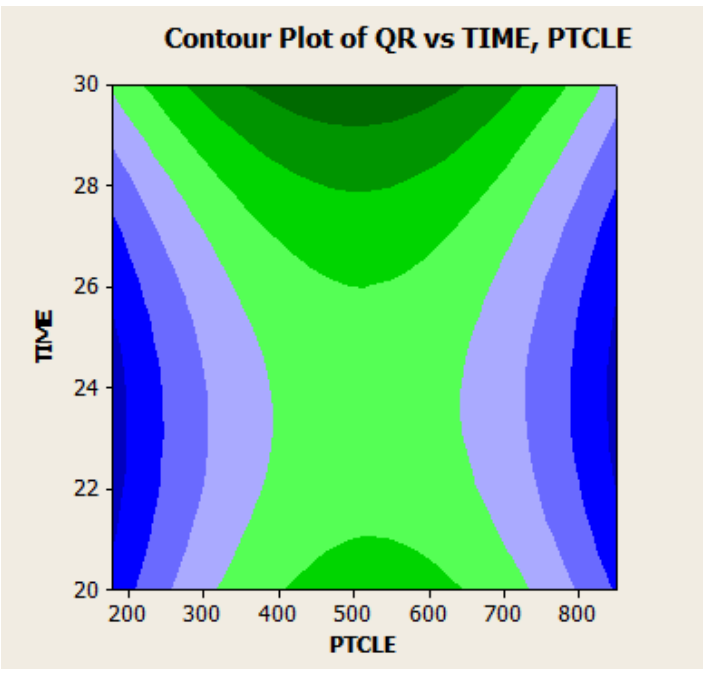

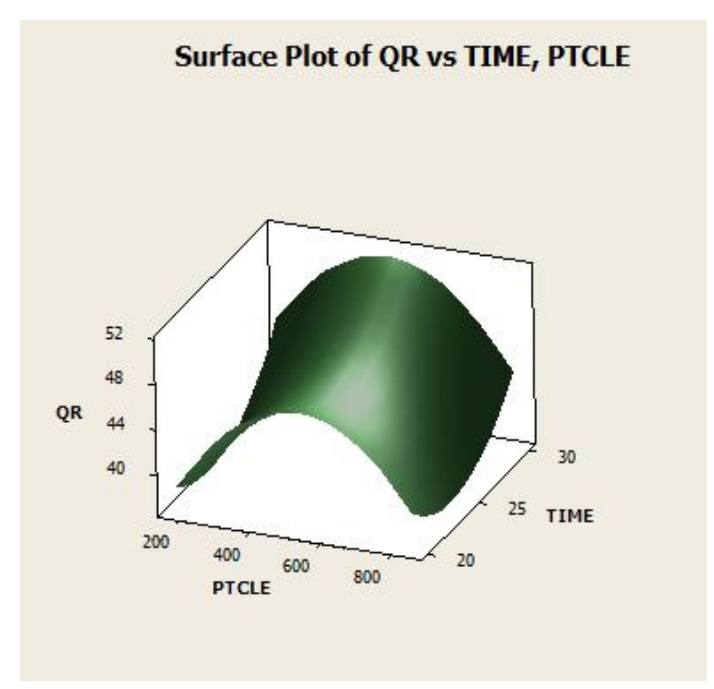


b)
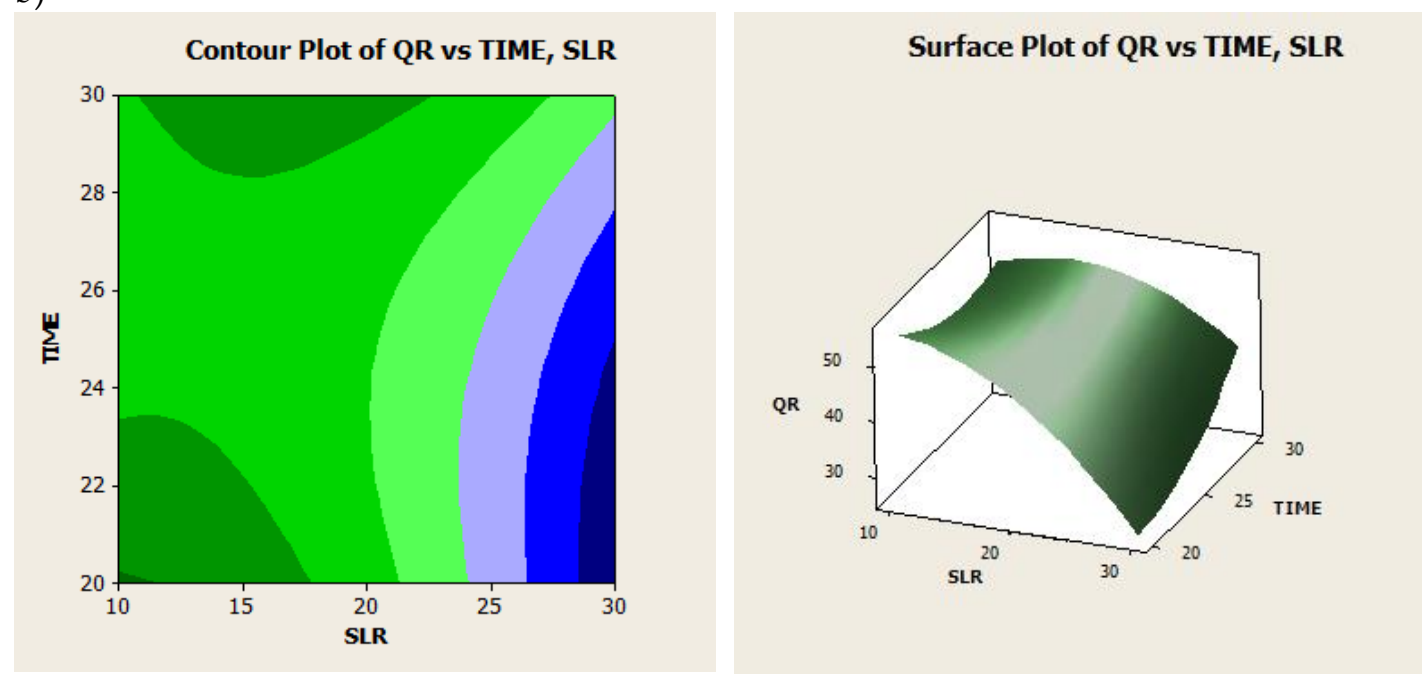

c)
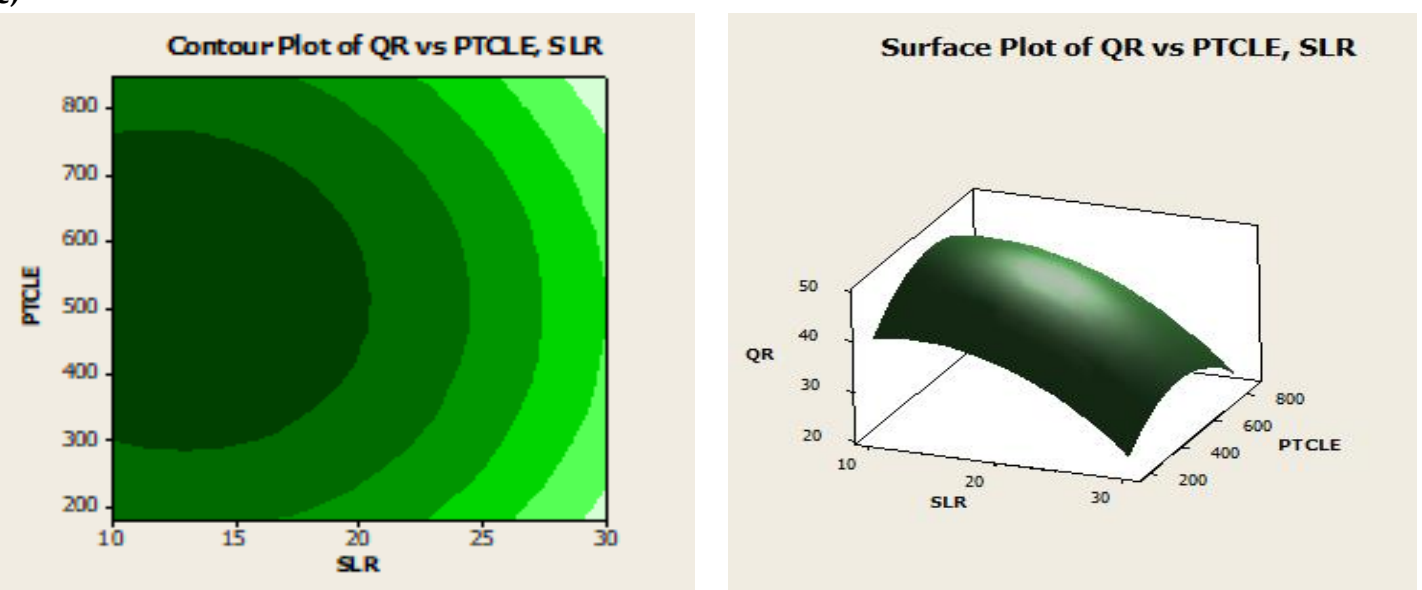

Figure 2. 2D contour plot (left) and 3D (right) showing the effects of time and particle size, time and SLR (b) and particle and SLR (c) on quercitrin content.

(a)
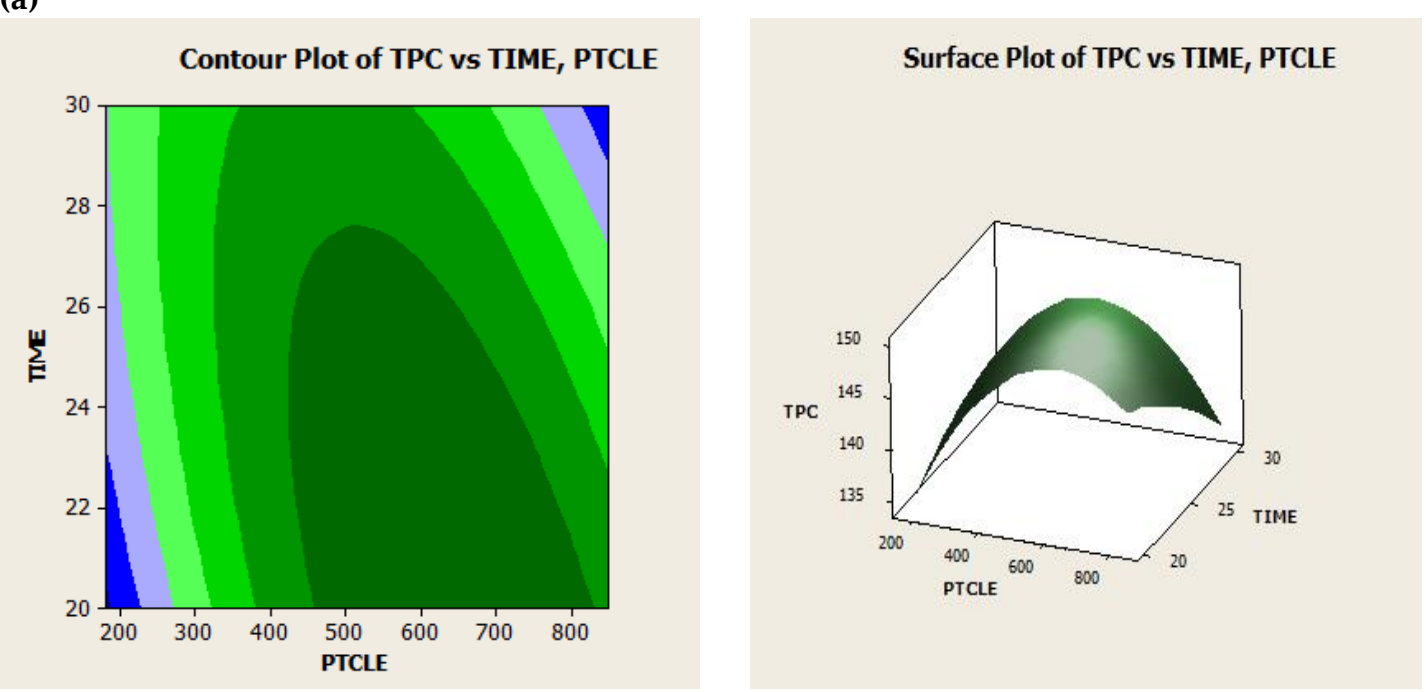
(b)
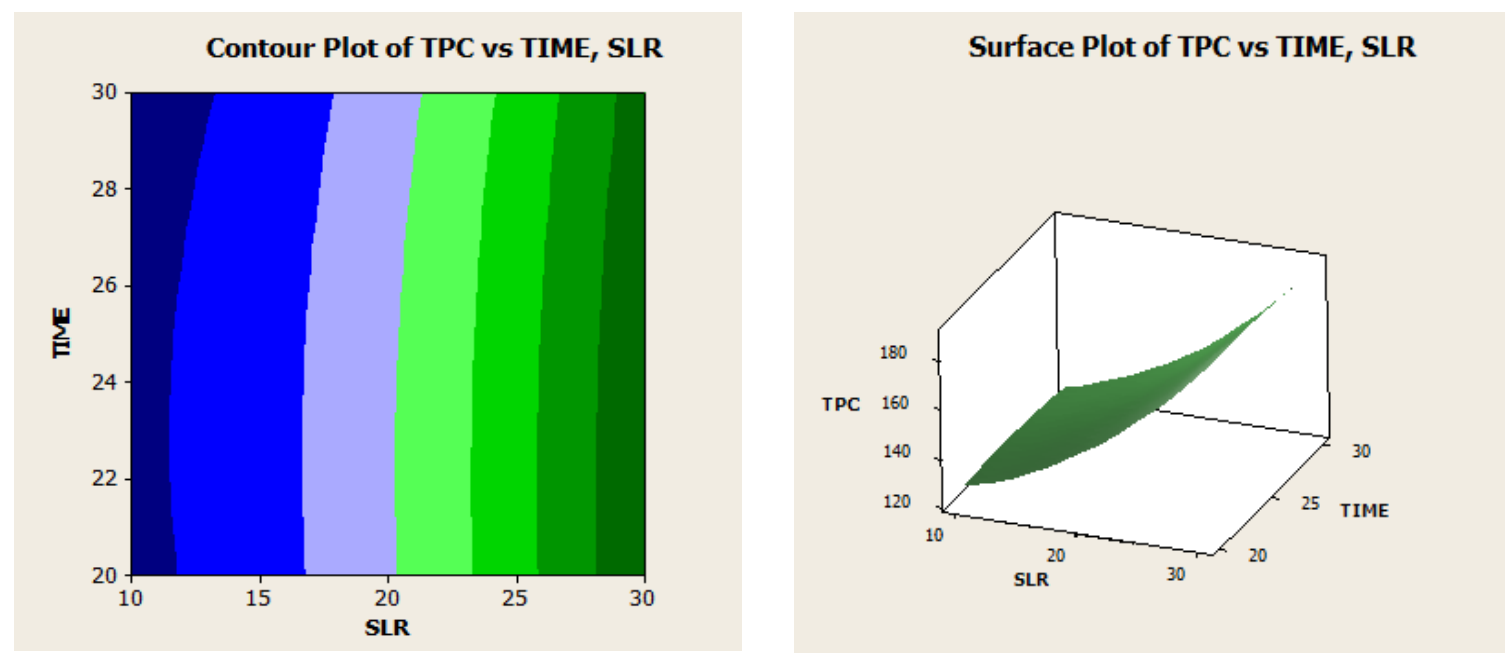

c)
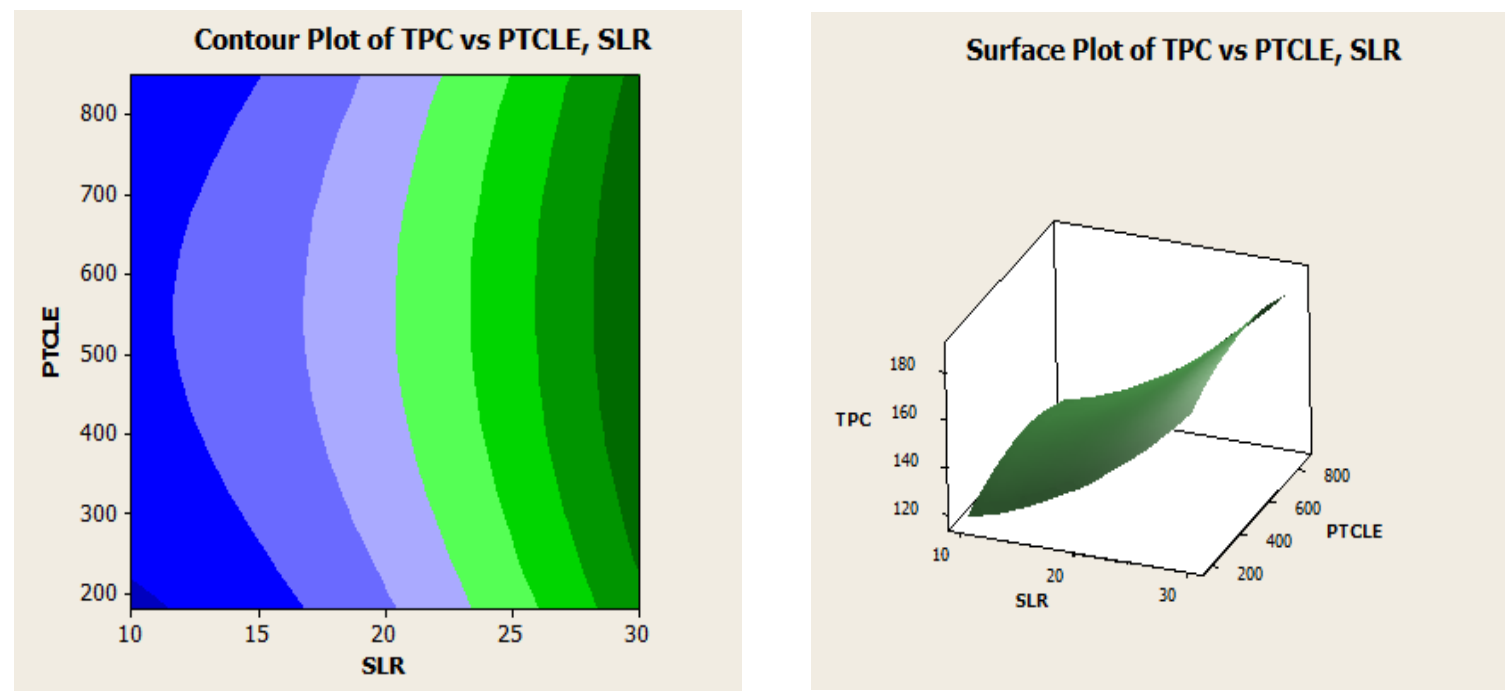

Figure 3. 2D contour plot (left) and 3D surface plot (right) showing the effects of time and particle size, time and SLR (b) and particle and SLR (c), on total phenolic content.

Comparison of ultrasound-assisted extraction with Soxhlet. UAE is known as a novel extraction method as it presents various advantages such as higher extraction efficiency, lower solvent consumption, and shorter extraction time ${ }^{54,55}$. In the literature, many studies have been carried out to compare the influence of extraction methods on extraction yield such as bioactive compounds, phenolic compounds, and antioxidant properties for various plant species 56,57. In particular, extraction by ultrasonic and microwave techniques have proved to be the most effective extraction methods for higher recovery of bioactive compounds from Panax ginseng and Gingko biloba ${ }^{56}$. In a previous study, the effect of different methods on ascorbic acid content from $C$. caudatus was compared between UAE, maceration and Soxhlet ${ }^{36}$. Their results indicate that the UAE method extracted higher ascorbic acid content, presenting $26.59 \mathrm{mg} / \mathrm{g}$ ascorbic acid. However, there are no reports on the extraction of bioactive phenolic compounds, particularly quercitrin from C. caudatus. Furthermore, the comparison of UAE with other extraction methods for recovery of bioactive compounds from C. caudatus are also scarce and not yet discussed so far. Due to limitations, this study was carried out to compare the efficiency of the UAE method (under optimised conditions) and the conventional method by Soxhlet on the extraction yield of quercitrin, total phenolic content and antioxidant content from C. caudatus. The results are shown in Table 5. 
The results of quercitrin, total phenolic content and antioxidant property extracted using UAE are higher than from the Soxhlet. This proved that UAE has successfully enhanced the extraction yields. On the other hand, an investigation by Seyedreihani et al. ${ }^{35}$ depicted that the quercitrin content in the C. caudatus aqueous extract was prepared in a shaking water bath was $36.90 \mathrm{mg} / \mathrm{g}$. The results were much lower than that prepared by the UAE method. In a previous study by Andarwulan et al. ${ }^{58}$ the sum of the flavonoids content (quercetin, kaempferol, luteolin, apigenin) on a dry basis was $3.72 \mathrm{mg} / \mathrm{g}$. Compared with the results of this study, the quercitrin which is a major flavonoids constituent in the plant extract was 11-fold higher than the reported sum flavonoids compound. Sharifuldin et al., ${ }^{10}$ reported the average value of quercitrin that was extracted with $75 \%$ ethanolic extract in Soxhlet ranged from 11 to $8.13 \% \mathrm{w} / \mathrm{w}$ DW. The difference in results could be associated with the process of extraction involved. The antioxidant property of the extract-based DPPH method was $20.83 \pm 1.33 \mathrm{mg} / \mathrm{L}$ (in IC 50 ). This result implied significant and notably 0.57 -fold higher than the results produced by the Soxhlet method. Interestingly, this value is also close to the IC 50 of the standard ascorbic acid value at $13.25 \pm 0.45 \mathrm{mg} / \mathrm{L}$. Summarising, the results demonstrated that the extraction method plays an important role in the recovery of extraction yield. UAE was found to be an effective method to increase the yield of quercitrin, total phenolic content and antioxidant property from C. caudatus leaves extract. Nevertheless, the markedly shorter extraction time of UAE and the reduction in solvent volume required, make UAE more efficient than the Soxhlet method.

\begin{tabular}{cccc}
\hline \multicolumn{3}{c}{ Extraction Yield } \\
\hline Method & Quercitrin, $(\mathrm{mg} / \mathrm{g})$ & $\begin{array}{c}\text { Total phenolic } \\
\text { content }(\mathrm{mg} / \mathrm{g})\end{array}$ & $\mathrm{IC} 50(\mathrm{mg} / \mathrm{L})$ \\
\hline Soxhlet & $35.50 \pm 0.24$ & $125.97 \pm 1.64$ & $36.80 \pm 0.68$ \\
UAE & $42.57 \pm 0.51$ & $169.75 \pm 0.63$ & $20.83 \pm 1.33$ \\
\hline
\end{tabular}

Table 5: Comparison of extraction yield between UAE and Soxhlet methods

Evaluation of the antimicrobial potential of $C$. caudatus extract. The antimicrobial potential of $C$. caudatus extract was determined against two human pathogenic bacteria; Staphylococcus aureus (S. aureus) and Escherichia coli (E. coli). Results of the inhibition growth of these Gram-positive bacteria and Gram-negative bacteria, present their apparent clear zone as shown in Table 6. After incubation at $37^{\circ} \mathrm{C}$ for $24 \mathrm{~h}$, the inhibition growth of $S$. aureus had produced a clear zone of diameter $24.67 \pm$ $0.57 \mathrm{~mm}$, while $E$. coli had produced a clear zone of diameter $24.5 \pm 0.50 \mathrm{~mm}$, respectively. These results were compared to the positive control of Streptomycin which had produced a clear zone diameter of $24.11 \pm 0.12 \mathrm{~mm}$. The findings proved that the sample treated with $C$. caudatus extract produced a similar inhibition to the Streptomycin in reducing the number of surviving bacteria. The results revealed the capabilities of the extract as an anti-microbial agent, similar to a previous study $43,59,60$. Several flavonoid derivatives have been proposed in bacterial resistance such as flavones and flavonoids ${ }^{61}$. In C. caudatus, a flavonoid produced by four isolated endophytic bacteria inhibits a human microbial pathogen ${ }^{43}$. Quercetin and its derivatives have been proposed and studied elsewhere to produce an extraordinary effect of bacterial resistance against several human pathogenic bacteria such as Staphylococcus aureus, Staphylococcus epidermidis, Porphyromonas gingivalis, Bacillus subtilis and Escherichia coli 62-64.

\begin{tabular}{ccc}
\hline & \multicolumn{2}{c}{ Zone of inhibition (mm) } \\
Sample & Staphylococcus aureus & Escherichia coli \\
\hline C.caudatus extract & $22.67 \pm 0.57$ & $21.5 \pm 0.50$ \\
\hline Streptomycin & $24.11 \pm 0.12$ & $24.11 \pm 0.12$ \\
\hline
\end{tabular}

Table 6 : Antimicrobial activity of $C$. caudatus leaves extract 
Fourier Transform Infrared (FTIR) for fingerprint analysis. The presence of the quercitrin compound in C. caudatus leaves extract was analyzed using Fourier Transform Infrared (FTIR). The full spectra of $C$. caudatus leaves extract and the quercitrin standard is shown in Figure 4 . In the first region of spectra (3200 to $\left.3300 \mathrm{~cm}^{-1}\right)$, the broad peak of hydroxyl $(-\mathrm{OH})$ was observed for both extract and standard. Three functional groups were attributed to alkanes $(\mathrm{C}-\mathrm{H})$, alkenes $(-\mathrm{C}=\mathrm{C})$ and ether $(\mathrm{C}-$ O), that appeared at $2831.20 \mathrm{~cm}^{-1}, 1664.63 \mathrm{~cm}^{-1}$ and $1113.5 \mathrm{~cm}^{-1}$, respectively. Only the group ester $(C=O)$ showed a significant peak at $1737.86 \mathrm{~cm}^{-1}$ in the $Q R$ standard. The functional group of esters were presented at the lower concentration in the extract. The previous study done by Gunasekaran et al. ${ }^{65}$ reported that the FTIR spectra of freeze-dried C. caudatus observed the presence of major hydroxyl (O-H) that identified at 3500 to $3000 \mathrm{~cm}^{-1}$ and putative carbonyl $(\mathrm{C}-\mathrm{O} \& \mathrm{C}=\mathrm{O}$ ) that was identified in the region between 1750 to $1500 \mathrm{~cm}^{-1}$ and 1200 to $1000 \mathrm{~cm}^{-1}$. The FTIR analysis of bioactive quercitrin in M. malabthricum ethanolic extract successfully characterised five functional groups, similar to this finding by Azri ${ }^{50}$. In addition, the presence of five functional groups of the hydroxyl group, alkanes, alkenes, ester, and ether correspond to quercitrin peaks as indicated in the chemical structure.

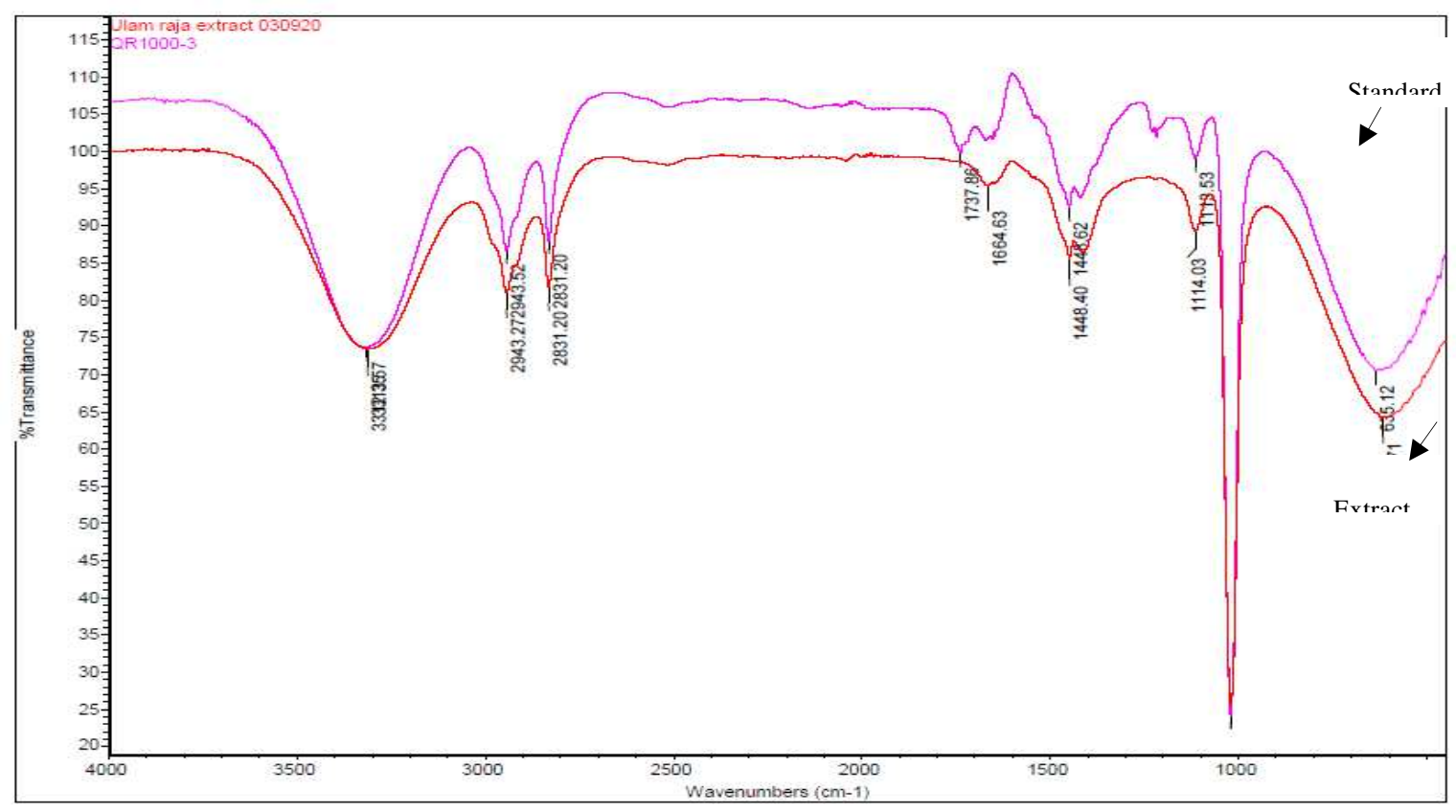

Figure 4: FTIR spectras of C. caudatus leaves extract and the quercitrin standard

\section{Conclusions}

To the best of the knowledge of the authors, this study reports for the first time concerning the UAE method used for extraction of both quercitrin and total phenolic content from C. caudatus leaves. According to the results, the optimum yield of quercitrin and total phenolic content were $42.57 \mathrm{mg} / \mathrm{g}$ and $169.75 \mathrm{mg} / \mathrm{g}$ respectively GAE/gram. The optimum extraction variables were $1: 28(\mathrm{~g} / \mathrm{mL})$, particle size $485 \mu \mathrm{m}$ and extraction time $30 \mathrm{~min}$. The UAE method has been proven to increase the yield of the extracted components and to have more advantages (shorter time, lower solvent amount, and low operational cost) over the Soxhlet extraction method. The results revealed the capabilities of the extract as an anti-microbial agent. This developed UAE method can contribute to the 
development of extraction protocols, or for further fractionation of bioactive compounds from $C$. caudatus leaves or other medicinal plants.

\section{References}

1. Moshawih, S., Cheeme, M. S., Ahmad, Z., Zakaria, Z. A. \& Hakim, M. N. A Comprehensive Review on Cosmos caudatus (Ulam Raja): Pharmacology, Ethnopharmacology, and Phytochemistry. Int. Res. J. Educ. Sci. eISSN 2550-2158 Vol. (2017). doi:10.1007/s00170-013-4743-1

2. Cheng, S. H., Yusof, B.-N. M., Hamid, A. \& Ismail, A. The King of Salad, Ulam raja (Cosmos caudatus) in Functional Food: Wonder of the World. (UPM press, 2017).

3. Chiang Chan, E. W. et al. Antioxidant properties of selected fresh and processed herbs and vegetables. Free Radicals Antioxidants (2014). doi:10.5530/fra.2014.1.7

4. Uzbek, U. H. \& Shahidan, W. N. S. Tasty herb that heals: A review of Cosmos caudatus (Ulam raja) and its potential uses in dentistry. World J. Dent. 10, 321-324 (2019).

5. Abdul Rahman, H. et al. Anti-obesity and antioxidant activities of selected medicinal plants and phytochemical profiling of bioactive compounds. Int. J. Food Prop. (2017). doi:10.1080/10942912.2016.1247098

6. Lia., A., Kusnandar., A., Sukrasno, Irda., F. \& Rini., I. Antihypertensive potency of wild cosmos (cosmos caudatus kunth, asteraceae) leaf extract. J. Pharmacol. Toxicol. (2012). doi:10.3923/jpt.2012.359.368

7. Wong, S. P., Leong, L. P. \& William Koh, J. H. Antioxidant activities of aqueous extracts of selected plants. Food Chem. 99, 775-783 (2006).

8. Mustafa, R. A., Hamid, A. A., Mohamed, S. \& Bakar, F. A. Total phenolic compounds, flavonoids, and radical scavenging activity of 21 selected tropical plants. J. Food Sci. (2010). doi:10.1111/j.17503841.2009.01401.x

9. Cheng, S. H., Barakatun-Nisak, M. Y., Anthony, J. \& Ismail, A. Potential medicinal benefits of Cosmos caudatus (Ulam Raja): A scoping review. Journal of Research in Medical Sciences (2015). doi:10.4103/17351995.172796

10. Sharifuldin, M. M. A., Ismail, Z., Aisha, A. F. A., Seow, E. K. \& Beh, H. K. Quantification of rutin, quercitrin and quercetin in Cosmos caudatus Kunth by reverse phase high performance liquid chromatography. Qual. Assur. Saf. Crop. Foods (2016). doi:10.3920/QAS2015.0839

11. Mediani, A., Abas, F., Khatib, A. \& Tan, C. P. Cosmos Caudatus as a potential source of polyphenolic compounds: Optimisation of oven drying conditions and characterisation of its functional properties. Molecules 18, 10452-10464 (2013).

12. Seyedreihani, S. F., Tan, T. C., Alkarkhi, A. F. M. \& Easa, A. M. Total phenolic content and antioxidant activity of Ulam raja (Cosmos caudatus) and quantification of its selected marker compounds: Effect of extraction. Int. J. Food Prop. (2017). doi:10.1080/10942912.2016.1155055

13. Li, X., Jiang, Q., Wang, T., Liu, J. \& Chen, D. Comparison of the antioxidant effects of quercitrin and isoquercitrin: Understanding the role of the 6"-OH group. Molecules 21, (2016).

14. Soberón, J. R., Sgariglia, M. A., Sampietro, D. A., Quiroga, E. N. \& Vattuone, M. A. Antibacterial activity of plant extracts from northwestern Argentina. J. Appl. Microbiol. 102, 1450-1461 (2007).

15. Cruz, E. A. et al. International Immunopharmacology Immunomodulatory pretreatment with Kalanchoe pinnata extract and its quercitrin $\mathrm{fl}$ avonoid effectively protects mice against fatal anaphylactic shock. 8, 1616-1621 (2008).

16. Mahdi, A. A. et al. Enhancing bio-recovery of bioactive compounds extracted from Citrus medica L. Var. sarcodactylis: optimization performance of integrated of pulsed-ultrasonic/microwave technique. J. Food 
Meas. Charact. 13, 1661-1673 (2019).

17. Ameer, K., Shahbaz, H. M. \& Kwon, J. H. Green Extraction Methods for Polyphenols from Plant Matrices and Their Byproducts: A Review. Comprehensive Reviews in Food Science and Food Safety 16, (2017).

18. Barba, F. J., Zhu, Z., Koubaa, M., Sant'Ana, A. S. \& Orlien, V. Green alternative methods for the extraction of antioxidant bioactive compounds from winery wastes and by-products: A review. Trends in Food Science and Technology 49, (2016).

19. Azmin, S. N. H. M. et al. Herbal processing and extraction technologies. Sep. Purif. Rev. 45, 305-320 (2016).

20. Chemat, F. et al. Review of Green Food Processing techniques. Preservation, transformation, and extraction. Innovative Food Science and Emerging Technologies 41, (2017).

21. Chemat, F., Vian, M. A. \& Cravotto, G. Green extraction of natural products: Concept and principles. Int. J. Mol. Sci. 13, 8615-8627 (2012).

22. Pradal, D., Vauchel, P., Decossin, S., Dhulster, P. \& Dimitrov, K. Kinetics of ultrasound-assisted extraction of antioxidant polyphenols from food by-products: Extraction and energy consumption optimization. Ultrason. Sonochem. 32, 137-146 (2016).

23. Da Porto, C. \& Natolino, A. Extraction kinetic modelling of total polyphenols and total anthocyanins from saffron floral bio-residues: Comparison of extraction methods. Food Chem. 258, 137-143 (2018).

24. Dumitraşcu, L., Enachi, E., Stănciuc, N. \& Aprodu, I. Optimization of ultrasound assisted extraction of phenolic compounds from cornelian cherry fruits using response surface methodology. CYTA - J. Food 17, 814-823 (2019).

25. Dranca, F. \& Oroian, M. Optimization of ultrasound-assisted extraction of total monomeric anthocyanin (TMA) and total phenolic content (TPC) from eggplant (Solanum melongena L.) peel. Ultrason. Sonochem. 31, 637-646 (2016).

26. Umaña, M., Eim, V., Garau, C., Rosselló, C. \& Simal, S. Ultrasound-assisted extraction of ergosterol and antioxidant components from mushroom by-products and the attainment of a $\beta$-glucan rich residue. Food Chem. 332, (2020).

27. Wen, C. et al. Advances in ultrasound assisted extraction of bioactive compounds from cash crops - A review. Ultrasonics Sonochemistry (2018). doi:10.1016/j.ultsonch.2018.07.018

28. F., C. et al. Ultrasound assisted extraction of food and natural products. Mechanisms, techniques, combinations, protocols and applications. A review. Ultrason. Sonochem. 34, 540-560 (2017).

29. Mehmood, A. et al. Optimization of total phenolic contents, antioxidant, and in-vitro xanthine oxidase inhibitory activity of sunflower head. CYTA - J. Food 16, 957-964 (2018).

30. Belwal, T. et al. Optimization model for ultrasonic-assisted and scale-up extraction of anthocyanins from Pyrus communis 'Starkrimson' fruit peel. Food Chem. 297, (2019).

31. Liu, X., Luo, G., Wang, L. \& Yuan, W. Optimization of antioxidant extraction from edible brown algae Ascophyllum nodosum using response surface methodology. Food Bioprod. Process. 114, 205-215 (2019).

32. Chen, F., Zhang, Q., Fei, S., Gu, H. \& Yang, L. Optimization of ultrasonic circulating extraction of samara oil from Acer saccharum using combination of Plackett-Burman design and Box-Behnken design. Ultrason. Sonochem. 35, 161-175 (2017).

33. Surin, S. et al. Optimization of ultrasonic-assisted extraction of polysaccharides from purple glutinous rice bran (Oryza sativa L.) and their antioxidant activities. Sci. Rep. 10, 1-10 (2020).

34. Arteaga-Crespo, Y., Radice, M., Bravo-Sanchez, L. R., García-Quintana, Y. \& Scalvenzi, L. Optimisation of ultrasound-assisted extraction of phenolic antioxidants from Ilex guayusa Loes. leaves using response surface methodology. Heliyon 6, 0-7 (2020). 
35. Seyedreihani, S. F., Tan, T. C., Alkarkhi, A. F. M. \& Easa, A. M. Total phenolic content and antioxidant activity of Ulam raja (Cosmos caudatus) and quantification of its selected marker compounds: Effect of extraction. Int. J. Food Prop. 20, 260-270 (2017).

36. Mohd Khairi, N. A. Antioxidant Activity of Cosmos caudatus Extracts by using different types of extraction methods. J. Chem. Inf. Model. (2013). doi:10.1017/CBO9781107415324.004

37. Sulaiman, S. F., Sajak, A. A. B., Ooi, K. L., Supriatno \& Seow, E. M. Effect of solvents in extracting polyphenols and antioxidants of selected raw vegetables. J. Food Compos. Anal. 24, 506-515 (2011).

38. Nasir, B. B. M. The effect of extraction parameters on antioxidant activity of Cosmos caudatus. 1-15 (2013).

39. Cheng, S. H., Khoo, H. E., Ismail, A., Abdul-Hamid, A. \& Barakatun-Nisak, M. Y. Influence of extraction solvents on Cosmos caudatus leaf antioxidant properties. Iran. J. Sci. Technol. Trans. A Sci. (2016). doi:10.1007/s40995-016-0007-x

40. Zulkiply, H. Optimization of extraction parameteres of total phenolic compound from Cosmos caudatus. (Universiti Malaysia Pahang, 2012).

41. Safdar, M. N. et al. Extraction and quantification of polyphenols from kinnow (Citrus reticulate L.) peel using ultrasound and maceration techniques. J. Food Drug Anal. 25, 488-500 (2017).

42. Saidan, N. H. et al. Selected metabolites profiling of Orthosiphon stamineus Benth leaves extracts combined with chemometrics analysis and correlation with biological activities. BMC Complement. Altern. Med. 15, 1-12 (2015).

43. Ramadhan, F. et al. Flavonoids from endophytic bacteria of cosmos caudatus Kunth. Leaf as anticancer and antimicrobial. Asian J. Pharm. Clin. Res. 11, 200-204 (2018).

44. Pandey, A., Belwal, T., Sekar, K. C., Bhatt, I. D. \& Rawal, R. S. Optimization of ultrasonic-assisted extraction (UAE) of phenolics and antioxidant compounds from rhizomes of Rheum moorcroftianum using response surface methodology (RSM). Ind. Crops Prod. 119, 218-225 (2018).

45. Chen, S. et al. Simultaneous optimization of the ultrasound-assisted extraction for phenolic compounds content and antioxidant activity of Lycium ruthenicum Murr. fruit using response surface methodology. Food Chem. 242, 1-8 (2018).

46. Asfaram, A., Ghaedi, M., Hajati, S. \& Goudarzi, A. Synthesis of magnetic $\gamma$-Fe2O3-based nanomaterial for ultrasonic assisted dyes adsorption: Modeling and optimization. Ultrason. Sonochem. (2016). doi:10.1016/j.ultsonch.2016.04.011

47. Vuong, Q. V., Golding, J. B., Nguyen, M. \& Roach, P. D. Extraction and isolation of catechins from tea. J. Sep. Sci. 33, 3415-3428 (2010).

48. Li, X. et al. An efficient homogenate-microwave-assisted extraction of flavonols and anthocyanins from blackcurrant marc: Optimization using combination of Plackett-Burman design and Box-Behnken design. Ind. Crops Prod. 94, 834-847 (2016).

49. Vuong, Q. V., Golding, J. B., Stathopoulos, C. E., Nguyen, M. H. \& Roach, P. D. Optimizing conditions for the extraction of catechins from green tea using hot water. J. Sep. Sci. 34, 3099-3106 (2011).

50. Mohd Azrie Awang. Optimization and Fractionation of Quercitrin-rich Extreact from Melastoma Malabthricum Leves ans its Bioactivities. (UTM, 2019).

51. Yahya, F., Lu, T., Santos, R. C. D., Fryer, P. J. \& Bakalis, S. Supercritical carbon dioxide and solvent extraction of 2-acetyl-1-pyrroline from Pandan leaf: The effect of pre-treatment. J. Supercrit. Fluids 55, 200-207 (2010).

52. He, B. et al. Optimization of Ultrasound-Assisted Extraction of phenolic compounds and anthocyanins 
from blueberry (Vaccinium ashei) wine pomace. Food Chem. 204, 70-76 (2016).

53. Modeling, L. K., Amirah, N., Raisha, A., Chong, G. H. \& Abdullah, L. C. Thymol Concentration from Plectranthus Amboinicus. Processes 8, (2020).

54. Chemat, F. et al. Ultrasound assisted extraction of food and natural products. Mechanisms, techniques, combinations, protocols and applications. A review. Ultrason. Sonochem. 34, 540-560 (2017).

55. Saifullah, M., McCullum, R., McCluskey, A. \& Vuong, Q. Comparison of conventional extraction technique with ultrasound assisted extraction on recovery of phenolic compounds from lemon scented tea tree (Leptospermum petersonii) leaves. Heliyon 6, (2020).

56. Tsaltaki, C., Katsouli, M., Kekes, T., Chanioti, S. \& Tzia, C. Comparison study for the recovery of bioactive compounds from Tribulus terrestris, Panax ginseng, Gingko biloba, Lepidium meyenii, Turnera diffusa and Withania somnifera by using microwave-assisted, ultrasound-assisted and conventional extraction methods. Ind. Crops Prod. 142, 111875 (2019).

57. López, C. J. et al. Optimization and comparison of heat and ultrasound assisted extraction techniques to obtain anthocyanin compounds from Arbutus unedo L. Fruits. Food Chem. 264, (2018).

58. Nuri Andarwulana, Ratna Batarib, Diny Agustini Sandrasarib, Bradley Bolling, and H. \& Wijayab. Flavonoid content and antioxidant activity of vegetables from Indonesia. Food Chem. 121, 1231-1235 (2010).

59. Yusoff, N. A. H., Sanuan, F. M. \& Rukayadi, Y. Cosmos caudatus Kunth. extract reduced number of microflora in oyster mushroom (Pleurotus ostreatus). Int. Food Res. J. (2015). doi:10.1038/srep16862

60. Nazihah Mohd Salehan, Sariah Meon \& Intan Safinar Ismail. Antifungal Activity of Cosmos caudatus Extracts against Seven Economically ...: Discovery Service for Universiti Kebangsaan Malaysia. Int. J. Agric. Biol. (2013).

61. Farhadi, F., Khameneh, B., Iranshahi, M. \& Iranshahy, M. Antibacterial activity of flavonoids and their structure-activity relationship: An update review. Phyther. Res. 33, 13-40 (2019).

62. Siriwong, S., Teethaisong, Y., Thumanu, K., Dunkhunthod, B. \& Eumkeb, G. The synergy and mode of action of quercetin plus amoxicillin against amoxicillin-resistant Staphylococcus epidermidis. BMC Pharmacol. Toxicol. 17, 1-14 (2016).

63. Aderogba, M. A., Ndhlala, A. R., Rengasamy, K. R. R. \& Van Staden, J. Antimicrobial and selected in vitro enzyme inhibitory effects of leaf extracts, flavonols and indole alkaloids isolated from Croton menyharthii. Molecules 18, 12633-12644 (2013).

64. F.Geoghegan, R. W. K. W. and A. B. M. R. Inhibition of cholinesterase and amyloid-\&bgr; aggregation by resveratrol oligomers from Vitis amurensis. Phyther. Res. 22, 544-549 (2008).

65. Gunasekaran, D., Bunawan, H., Ismail, I. \& Noor, N. M. Data on Fourier transform-infrared of Cosmos caudatus Kunth. tissues analyzed with chemometric analysis. Data Br. (2018). doi:10.1016/j.dib.2018.06.025

\section{Acknowledgments}

Authors acknowledge to the technical research support team from Innovation Centre in Agritechnology, Universiti Teknologi Malaysia; Salimah Ab. Malek, Mohd Nadzreen Hidayat Sarjuni and Nur Hidayah Shadan for their support during the experimental work.

\section{Author Contributions:}

Conceptualization and supervision, L.C.A., P.Y.O.; Methodology, software and validation, L.N.A and P.Y.O. Original draft preparation L.N.A.; Editing and Review draft, S.N.A.A.R, P.Y.O Review of the final draft, L.C.A., P.Y.O., N.A.M.A and N.A.M.; Funding acquisition, L.C.A. All authors have read and agreed to the published version of the manuscript." 


\section{Competing interests}

The authors declare that no potential conflict of interest was reported by any of the authors to influence the work reported in this paper.

Correspondence and requests for material should be addressed to N.A.L. and L.C.A.

\section{Funding}

Financial aids for the publication was funded by Universiti Putra Malaysia. 
Figures

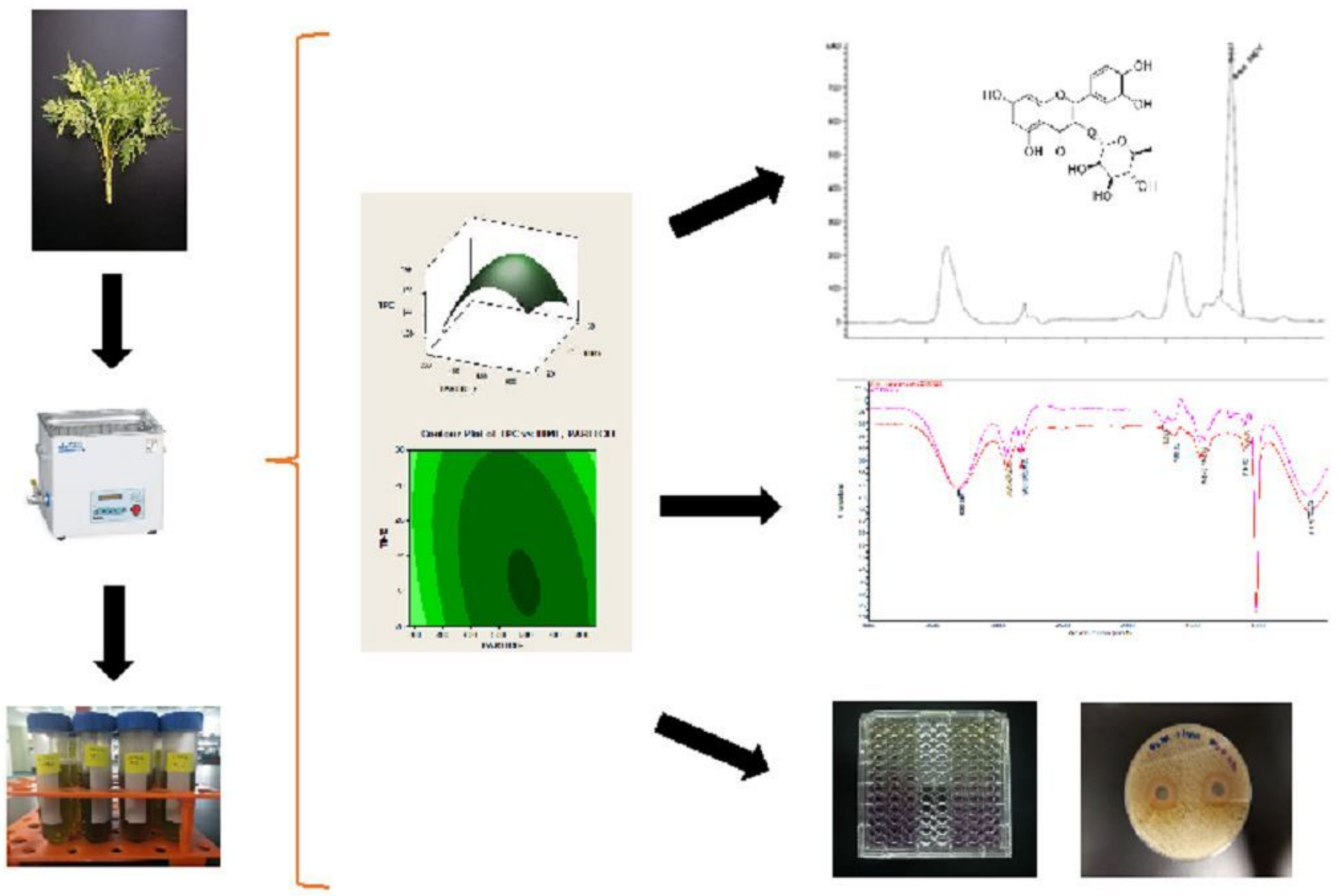

Figure 1

Process flow of the studied extraction process 
(a)
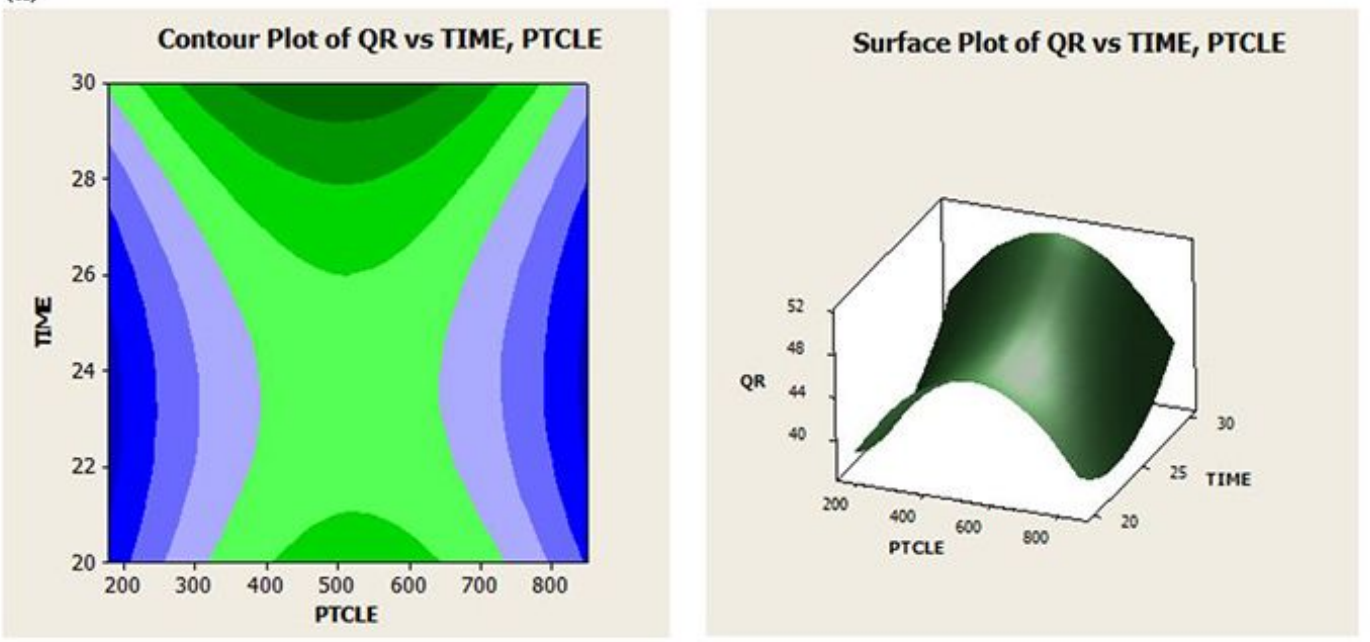

b)
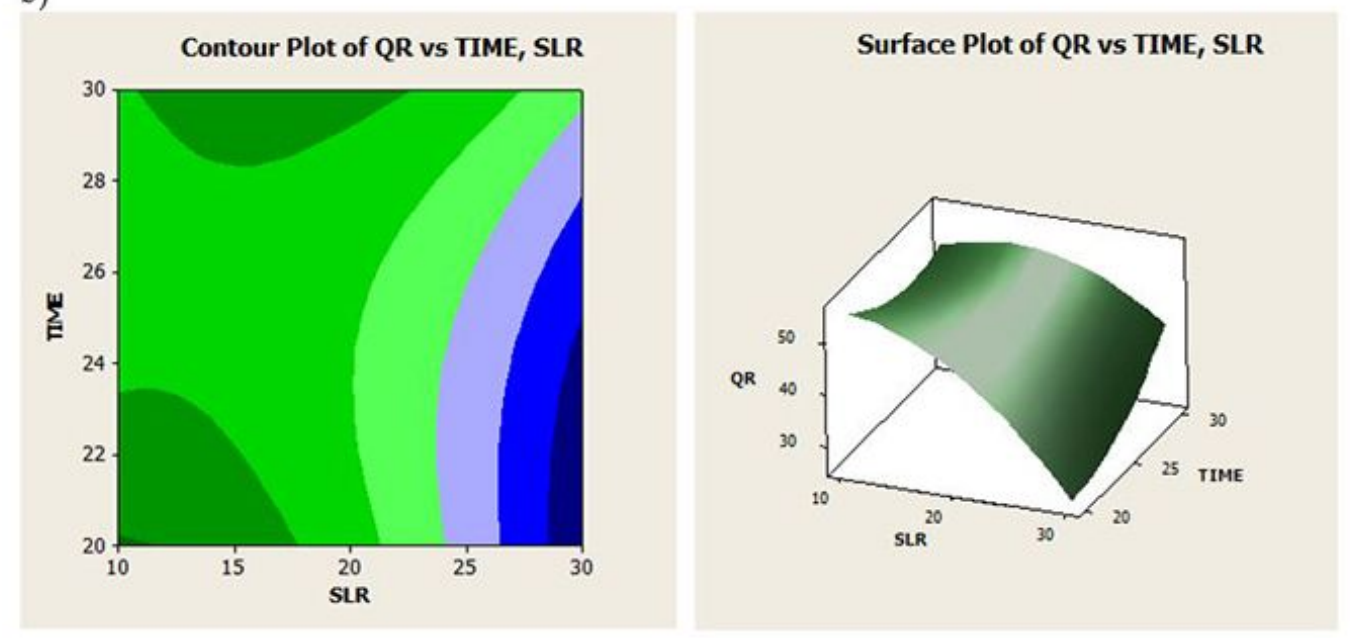

c)
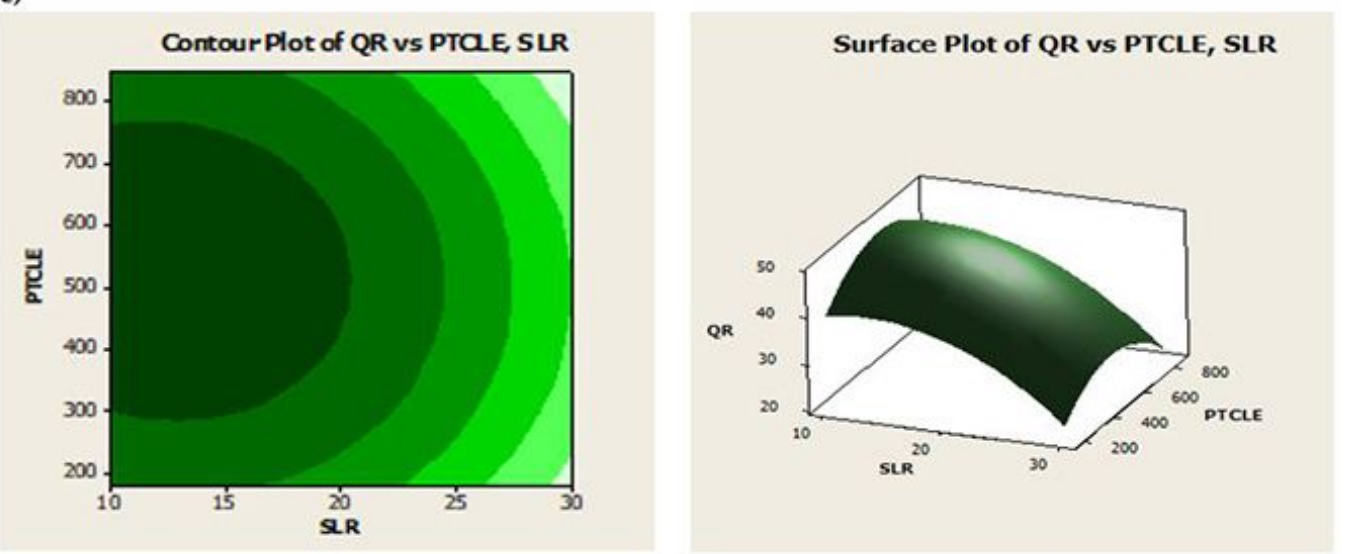

\section{Figure 2}

2D contour plot (left) and 3D (right) showing the effects of time and particle size, time and SLR (b) and particle and SLR (c) on quercitrin content. 
(a)

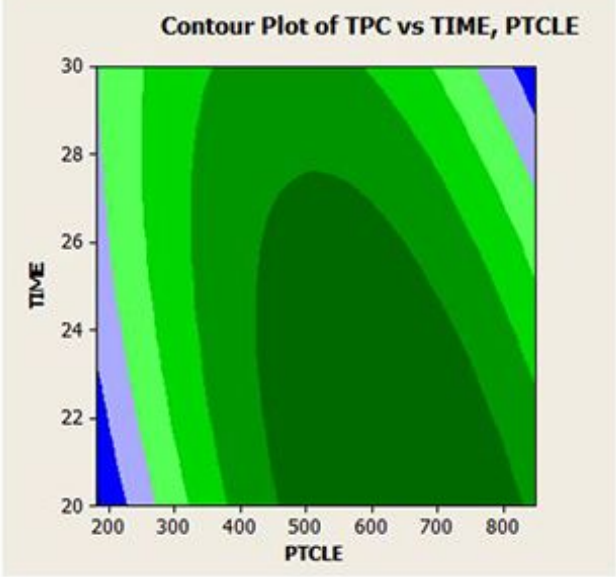

(b)

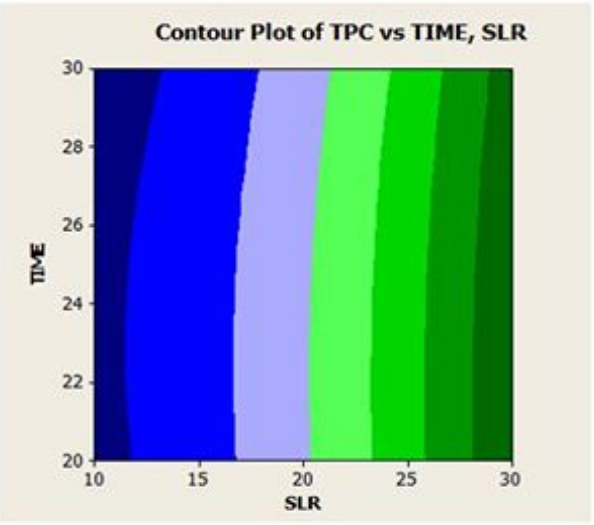

c)

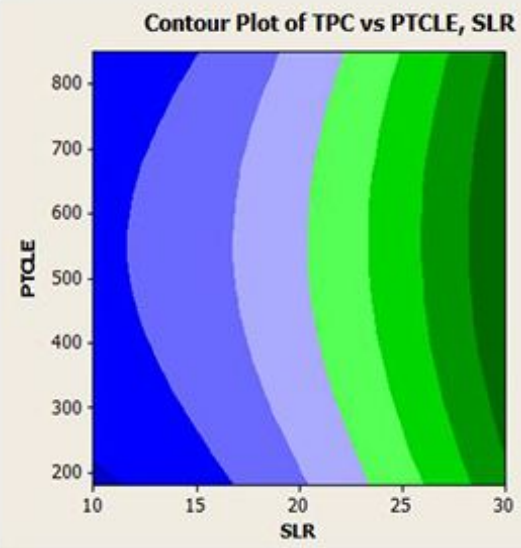

Surface Plot of TPC vs TIME, PTCLE
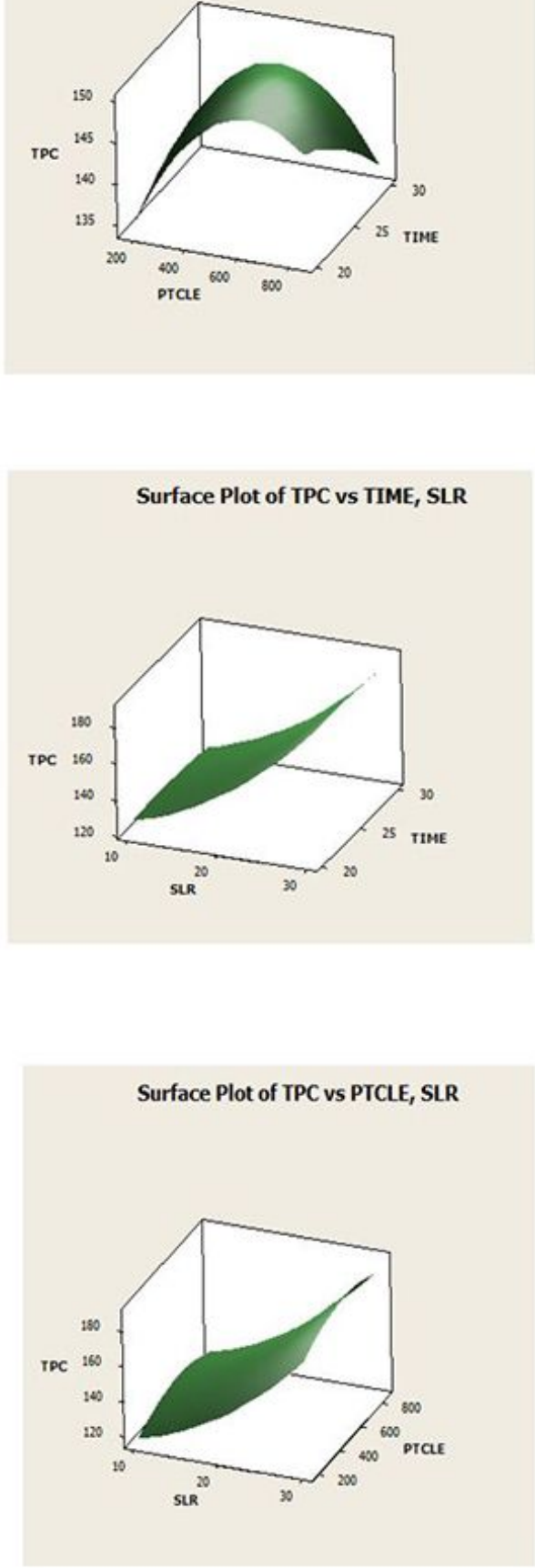

\section{Figure 3}

2D contour plot (left) and 3D surface plot (right) showing the effects of time and particle size, time and SLR (b) and particle and SLR (c), on total phenolic content. 


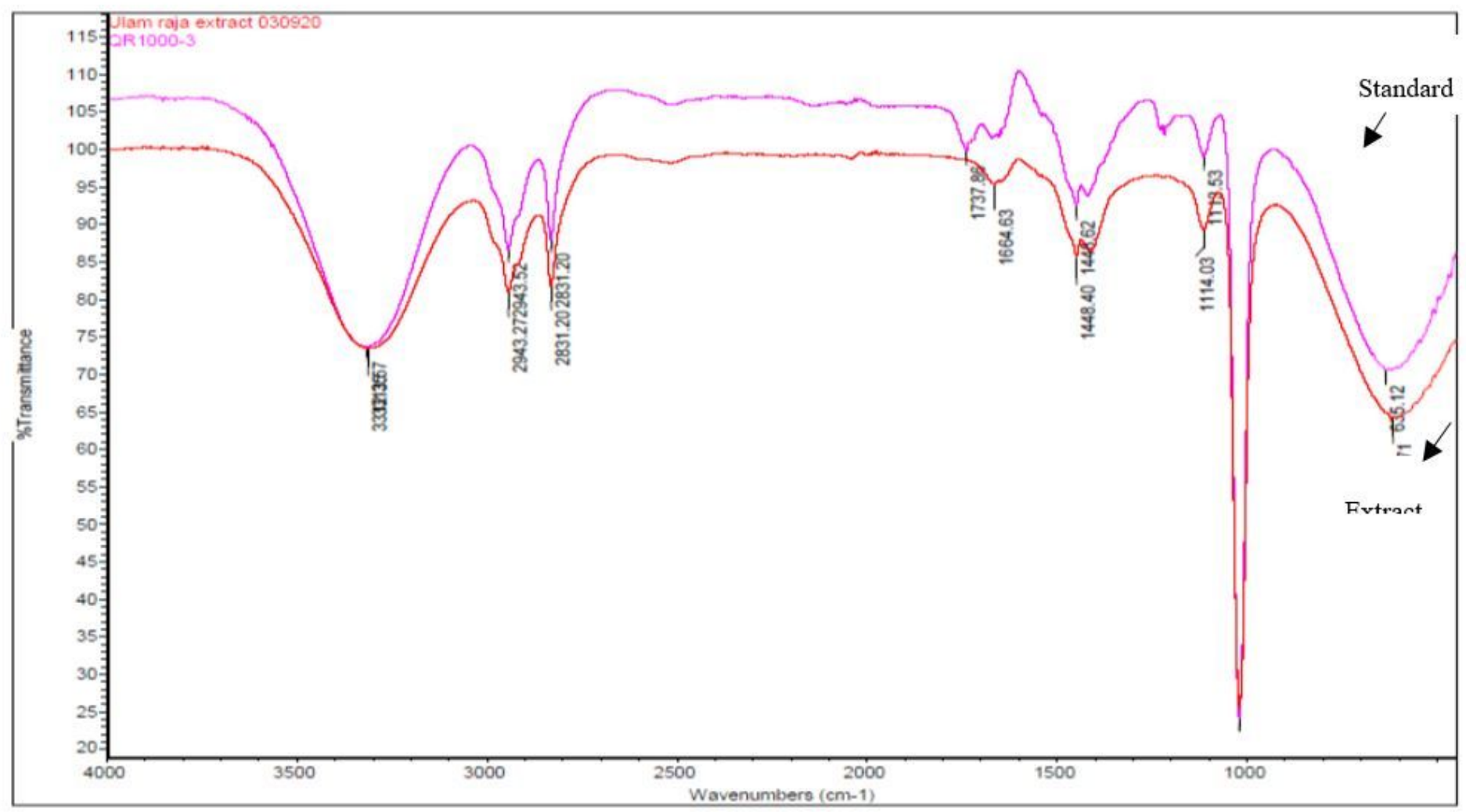

Figure 4

FTIR spectras of $\mathrm{C}$. caudatus leaves extract and the quercitrin standard 